\title{
Isolating the entire posterior left atrium improves surgical outcomes after the Cox maze procedure
}

\author{
Rochus K. Voeller, MD, Marci S. Bailey, RN, Andreas Zierer, MD, Shelly C. Lall, MD, Shun-ichiro Sakamoto, MD, \\ Kristen Aubuchon, Jennifer S. Lawton, MD, Nader Moazami, MD, Charles B. Huddleston, MD, Nabil A. Munfakh, MD, \\ Marc R. Moon, MD, Richard B. Schuessler, PhD, and Ralph J. Damiano, Jr, MD
}

From the Division of Cardiothoracic Surgery, Washington University School of Medicine, Barnes-Jewish Hospital, Saint Louis, Mo.

Ralph Damiano reports consulting and lecture fees from Atricure, Medtronic, and Medical CV and grant support from Atricure and Estech. Charles Huddleston reports equity ownership in Medtronic. Richard Schuessler reports lecture fees from Atricure and grant support from Atricure and Medtronic.

Supported in part by National Institutes of Health grants R01 HL032257-21 and F32 HL082129-02.

Read at the Eighty-seventh Annual Meeting of The American Association for Thoracic Surgery, Washington, DC, May 5-9, 2007.

Received for publication May 3, 2007; revisions received Sept 12, 2007; accepted for publication Oct 26, 2007.

Address for reprints: Ralph J. Damiano, Jr, MD, Washington University School of Medicine, Barnes-Jewish Hospital, Suite 3108 Queeny Tower, 1 Barnes-Jewish Hospital Plaza, Saint Louis, MO 63110 (E-mail: damianor@wustl.edu).

J Thorac Cardiovasc Surg 2008;135:870-7 0022-5223/\$34.00

Copyright (C) 2008 by The American Association for Thoracic Surgery

doi:10.1016/j.jtcvs.2007.10.063
Objectives: The importance of each ablation line in the Cox maze procedure for treatment of atrial fibrillation remains poorly defined. This study evaluated differences in surgical outcomes of the procedure performed either with a single connecting lesion between the right and left pulmonary vein isolations versus 2 connecting lesions (the box lesion), which isolated the entire posterior left atrium.

Methods: Data were collected prospectively on 137 patients who underwent the Cox maze procedure from April 2002 through September 2006. Before May 2004, the pulmonary veins were connected with a single bipolar radiofrequency ablation lesion $(\mathrm{n}=56)$, whereas after this time, a box lesion was routinely performed $(\mathrm{n}=81)$. The mean follow-up was $11.8 \pm 9.6$ months.

Results: The incidence of early atrial tachyarrhythmia was significantly higher in the single connecting lesion group compared with that in the box lesion group ( $71 \%$ vs $37 \%, P<.001)$. The overall freedom from atrial fibrillation recurrence was significantly higher in the box lesion group at $1(87 \%$ vs $69 \%, P=.015)$ and $3(96 \%$ vs $85 \%, P=.028)$ months. The use of antiarrhythmic drugs was significantly lower in the box lesion group at $3(35 \%$ vs $58 \%, P=.018)$ and $6(15 \%$ vs $44 \%, P=$ .002) months.

Conclusions: Isolating the entire posterior left atrium by creating a box lesion instead of a single connecting lesion between the pulmonary veins showed a significantly lower incidence of early atrial tachyarrhythmias, higher freedom from atrial fibrillation recurrence at 1 and 3 months, and lower use of antiarrhythmic drugs at 3 and 6 months. A complete box lesion should be included in all patients undergoing the Cox maze procedure.

A trial fibrillation (AF) is the most common sustained arrhythmia in the world, and its prevalence increases with age. ${ }^{1,2} \mathrm{AF}$ is associated with significant health care costs and is becoming a serious public health issue as our aging population continues to expand. ${ }^{3-5} \mathrm{In}$ fact, $\mathrm{AF}$ is accountable for about a quarter of all strokes in patients older than 80 years. ${ }^{4}$

In an attempt to cure this arrhythmia, the Cox maze procedure was developed after extensive experimental investigation at our institution. Introduced clinically in 1987, the Cox maze procedure became the gold standard for the surgical treatment of AF. The operation involved the creation of multiple surgical incisions on the right and left atria that were hypothesized to interrupt the macroreentrant circuits thought to be responsible for sustaining $\mathrm{AF}^{6}{ }^{6}$ The final iteration of the procedure, the Cox maze III procedure, was proved to be highly efficacious, with excellent long-term results. ${ }^{7-9}$ However, it was not widely accepted by practicing surgeons because of its technical complexity, invasiveness, and associated morbidity.

To simplify the procedure, groups around the world have recently used various energy sources to create linear lines of ablation on the atria to replace most of the incisions of the Cox maze III procedure. ${ }^{10-13}$ Ablation technology has made the procedure 
Abbreviation and Acronym

$\mathrm{AF}=$ atrial fibrillation

less invasive and more accessible to cardiac surgeons worldwide. At our institution, bipolar radiofrequency energy was chosen to replace the surgical incisions after extensive experimental studies. ${ }^{14-16}$ The bipolar radiofrequency ablationassisted Cox maze procedure, termed the Cox maze IV procedure, has had excellent results and has significantly shortened cardiopulmonary bypass and crossclamp times. ${ }^{17-21}$ A propensity analysis recently performed on patients who underwent either the Cox maze III or the Cox maze IV procedure found no difference in freedom from AF recurrence at 1 year. $^{22}$

The lesion set created in the ablation-assisted Cox maze IV procedure (Fig 1) is patterned after the original cut-andsew Cox maze III lesion set. This original lesion set was empirically based, and the importance of each of the incisions/ ablations in the lesion set has not been well defined.

The Cox maze IV procedure has been used exclusively by our group for the surgical treatment of AF since its clinical debut in 2002. The lesion set has remained the same over this time, with the exception of the technique to connect the right and left pulmonary veins (Figs 1 and 2). Initially, the right and left pulmonary vein lesions were connected only inferiorly with a single ablation line (nonbox lesion), leaving the posterior left atrium in electrical continuity with the remaining atrium. More recently, the right and left pulmonary vein lesions were connected both superiorly and inferiorly by using bipolar radiofrequency ablation, thereby completely isolating the posterior left atrium (box lesion).

The effect of completely electrically isolating the posterior left atrium in the Cox maze procedure, which is simply performed through the addition of a second ablation line between the superior right and left pulmonary veins, is unknown. Therefore the purpose of this study was to investigate the difference in outcomes between patients who underwent the Cox maze IV procedure with either the nonbox or the box lesion set in the posterior left atrium.

\section{Materials and Methods}

From April 2002 through September 2006, 137 patients underwent the bipolar radiofrequency ablation-assisted Cox maze IV procedure at Barnes-Jewish Hospital. From April 2002 through May 2004, all except 1 patient underwent the Cox maze IV procedure with the nonbox lesion set $(n=56)$. From June 2004 through October 2006, the Cox maze IV procedure with the box lesion was performed in all but 2 patients $(n=81)$. All operations were performed by the same surgeon (R.J.D.). One hundred twenty-one patients underwent the Cox maze procedure with the bipolar radiofrequency ablation system Atricure Isolator (Atricure, Inc, Cincinnati, Ohio). Sixteen patients had the procedure with the Medtronic Cardioblate BP Surgical Ablation

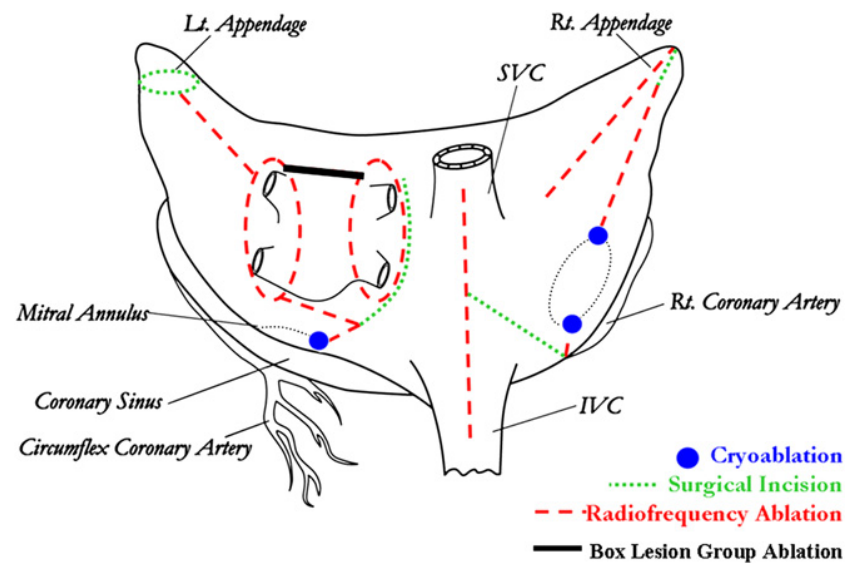

Figure 1. Posterior view of the atria illustrating the complete Cox maze IV lesion set. Patients either had a single ablation line connecting the inferior right and left pulmonary veins (nonbox lesion set) or had an additional ablation line connecting the superior right and left pulmonary veins (box lesion set), which electrically isolated the posterior left atrium. SVC, Superior vena cava; IVC, inferior vena cava; $L t$, left; $R t$, right. Adapted from Lall SC, Melby SJ, Voeller RK, Zierer A, Bailey MS, Guthrie TJ, et al. The effect of ablation technology on surgical outcomes after the Cox-maze procedure: A propensity analysis. J Thorac Cardiovasc Surg. 2007;133:389-96.

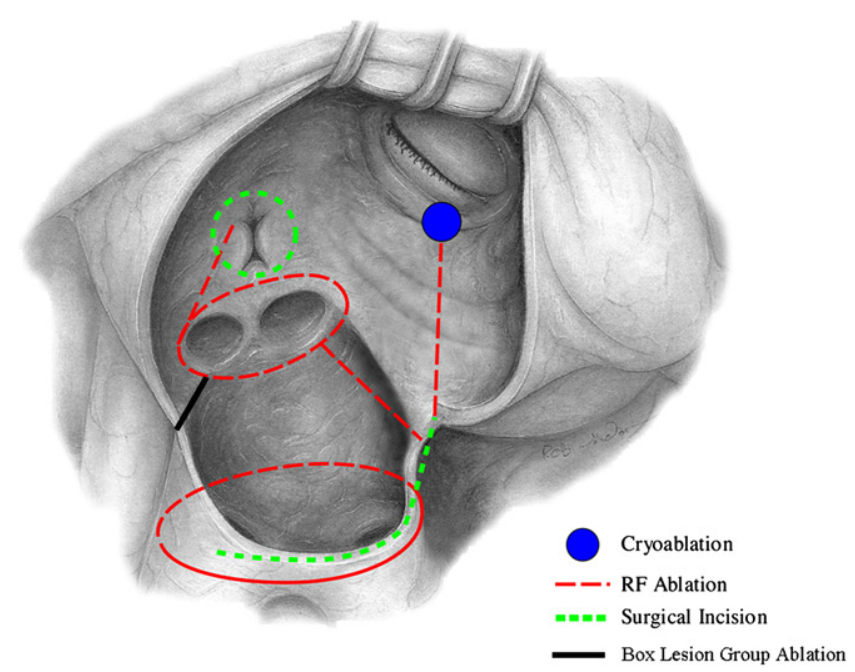

Figure 2. Endocardial view of the left atrium. Patients either had a single ablation line connecting the inferior right and left pulmonary veins (nonbox lesion set) or had an additional ablation line connecting the superior right and left pulmonary veins (box lesion set), which electrically isolated the posterior left atrium. RF, Radiofrequency. Adapted from Gaynor SL, Diodato MD, Prasad SM, Ishii Y, Schuessler RB, Bailey MS, et al. A prospective single-center clinical trial of a modified Cox maze procedure with bipolar radiofrequency ablation. $J$ Thorac Cardiovasc Surg. 2004;128:535-42. 
System (Medtronic, Inc, Minneapolis, Minn). This study was approved by the Washington University School of Medicine Institutional Review Board. Informed consent and permission for release of information were obtained from each patient.

\section{Surgical Technique}

The Cox maze IV procedure was performed by using cardiopulmonary bypass with bicaval cannulation. ${ }^{23}$ Patients underwent either a median sternotomy or a right minithoracotomy. ${ }^{24}$ Initially, the heart was perfused at $36^{\circ} \mathrm{C}$ to maintain sinus rhythm and to measure pacing thresholds from the pulmonary veins. The right and left pulmonary veins were bluntly dissected. If the patient was in AF, amiodarone was administered, and the patient was cardioverted. The pulmonary veins were then isolated by placing the jaw of the bipolar radiofrequency ablation device on the cuff of the atrial tissue surrounding the right and left pulmonary veins. Electrical isolation was documented after ablation by pacing from both the superior and inferior pulmonary veins at a stimulus strength of $20 \mathrm{~mA}$. In patients undergoing a right minithoracotomy, pacing was performed only from the right pulmonary veins.

The patients then underwent a Cox maze IV procedure, as previously described. ${ }^{17,20,23}$ Concomitant procedures performed in this study included coronary artery bypass grafting, mitral valve repair and replacement, aortic valve replacement, tricuspid valve replacement, closure of patent foramen ovale, atrial septal defect repair, left atrial reduction, septal myectomy, and resection of an intracardiac tumor.

\section{Postoperative Care and Follow-up}

Data were collected prospectively on all patients postoperatively, and follow-up was $100 \%$ complete. Prophylactic antiarrhythmic drugs were initiated immediately postoperatively, except in patients with heart block or junctional rhythm. Amiodarone was preferably used and was continued for 2 to 3 months postoperatively when it was discontinued if the patient was in sinus rhythm. Patients with postoperative atrial tachyarrhythmias were cardioverted between 1 and 4 weeks. Unless there were contraindications to anticoagulation, all patients were started on warfarin for 3 months, at which point it was discontinued if the patient was in sinus rhythm.

While in the hospital, all patients were continuously monitored for any arrhythmias. Any early atrial tachyarrhythmias (defined as $\mathrm{AF}$, atrial flutter, and other supraventricular tachycardias that occurred within 30 days after the operation) were documented.

\section{TABLE 1. Patient characteristics}

\begin{tabular}{lccc}
\hline \multicolumn{1}{c}{ Variables } & $\begin{array}{c}\text { Nonbox lesions } \\
(\mathbf{n}=\mathbf{5 6})\end{array}$ & $\begin{array}{c}\text { Box lesions } \\
(\mathbf{n}=\mathbf{8 1})\end{array}$ & $\boldsymbol{P}$ value \\
\hline Mean age (y) & $62.6 \pm 11.8$ & $60.2 \pm 12.6$ & .274 \\
Male sex (\%) & $31(55)$ & $53(65)$ & .285 \\
AF duration (mo) & $83.5 \pm 86.9$ & $76.6 \pm 86.9$ & .649 \\
Paroxysmal AF (\%) & $35(63)$ & $51(63)$ & 1.0 \\
NYHA class 3 or 4 (\%) & $30(54)$ & $49(60)$ & .483 \\
Mean LVEF (\%) & $48.8 \pm 13.3$ & $50.2 \pm 12.1$ & .543 \\
Failed catheter ablation (\%) & $6(11)$ & $10(12)$ & 1.0 \\
Neurologic indication (\%) & $3(5)$ & 0 & .066 \\
LA diameter (cm) & $5.8 \pm 1.3$ & $5.3 \pm 1.3$ & .055 \\
\hline
\end{tabular}

$A F$, Atrial fibrillation; NYHA, New York Heart Association; $L V E F$, left ventricular ejection fraction; $L A$, left atrium.
The incidence of early postoperative permanent pacemaker placement (within 30 days after the operation) was also recorded. Fourteen intraoperative and early postoperative outcome variables were analyzed for both groups of patients (nonbox vs box), which included cardiopulmonary bypass and crossclamp times, 30-day operative mortality, myocardial infarction, and stroke.

After discharge, all patients had scheduled office visits at 1, 3, 6 , and 12 months, followed by annual visits. At each follow-up visit, a history, physical examination, and electrocardiogram were obtained. If a patient could not return to our institution, telephone interviews were conducted, and electrocardiograms were obtained from referring physicians to document the heart rhythm. Patients with symptoms of palpitations were evaluated with electrocardiography, prolonged Holter monitoring ( $>24$ hours), or both to assess their heart rhythm. If patients were implanted with permanent pacemakers, interrogations were performed to determine the occurrence of AF. In the later part of our series, patients had 24-hour Holter monitoring at 3 months.

\section{Data Analysis}

Data were collected and entered into a patient database. Continuous data were expressed as means \pm standard deviations. Categorical data were expressed as counts and proportions. The clinical profiles of the 2 groups (nonbox lesion group vs box lesion group) were performed by using the paired $t$ test. The $\chi^{2}$ or Fisher exact tests were used to analyze differences among the categorical data. All statistical analysis was performed with the SPSS system for statistics (SPSS, Inc, Chicago, Ill).

\section{Results}

\section{Patient Demographics}

Patient demographics are categorized in Table 1. The characteristics of the 2 groups were similar because there were no differences in age, sex, AF type or duration, New York Heart Association class, left ventricular ejection fraction, or left atrial diameter between the groups. The mean left atrial diameter was slightly less in the box lesion group. However, it did not reach statistical significance.

The procedures performed on these patients are detailed in Table 2. There were no differences in the number of lone maze procedures. Fourteen $(25 \%)$ patients in the nonbox group had ischemic heart disease versus 12 (15\%) patients in the box group.

\section{Perioperative Results}

There was no difference in the cardiopulmonary bypass and crossclamp times between the 2 groups (Table 3 ). There also was no difference in operative mortality, incidence of postoperative myocardial infarction, stroke, reoperation for bleeding, permanent pacemaker placement, or median intensive care unit stay. However, there was a trend toward a reduction in the median hospital length of stay in the box lesion group (11 vs 9 days, $P=$.074). The only significant difference between the 2 groups was the incidence of early atrial tachyarrhythmias, which was significantly higher in the nonbox group $(71 \%$ vs $37 \%, P<.001)$. 
TABLE 2. Operative procedures

\begin{tabular}{|c|c|c|c|c|}
\hline Procedure types & Total $(n=137)$ & Nonbox lesions $(n=56)$ & Box lesions $(n=81)$ & $P$ value \\
\hline Lone CM IV (\%) & $50(36)$ & $22(39)$ & $28(35)$ & .593 \\
\hline CM IV + concomitant procedure & $87(64)$ & $34(61)$ & $53(65)$ & - \\
\hline $\mathrm{CM}+\mathrm{MV}$ procedure & 35 & 14 & 21 & - \\
\hline $\mathrm{CM}+\mathrm{MV}+\mathrm{TV}$ procedure & 9 & 4 & 5 & - \\
\hline $\mathrm{CM}+\mathrm{CABG}$ & 11 & 8 & 3 & - \\
\hline $\mathrm{CM}+\mathrm{CABG}+\mathrm{MV}$ procedure & 9 & 4 & 5 & - \\
\hline $\mathrm{CM}+\mathrm{AV}$ procedure & 7 & 0 & 7 & - \\
\hline $\mathrm{CM}+\mathrm{AV}+\mathrm{CABG}$ & 5 & 1 & 4 & - \\
\hline $\mathrm{CM}+\mathrm{MV}+\mathrm{AV}$ procedure & 3 & 1 & 2 & - \\
\hline $\mathrm{CM}+$ septal myectomy \pm other & 4 & 0 & 4 & - \\
\hline $\mathrm{CM}+$ miscellaneous procedure & 4 & 2 & 2 & - \\
\hline
\end{tabular}

$C M$, Cox maze procedure; $M V$, mitral valve; $T V$, tricuspid valve; $C A B G$, coronary artery bypass graft; $A V$, aortic valve.

\section{Late Outcomes}

No patient was lost to follow-up. The mean follow-up in the series was $11.8 \pm 9.6$ months. The median follow-up was 9.5 months (range, $0.8-38.2$ months). The difference in the mean follow-up duration between the nonbox and box lesion groups was statistically significant $(19.2 \pm 10.3$ vs $7.0 \pm 5.4$ months, $P<.001)$. There was no significant difference in the use of $\beta$-blockers or warfarin at any of the follow-up intervals. The use of $\beta$-blockers in the nonbox versus the box group was $46 \%$ versus $60 \%(P=.169)$ at 6 months and $33 \%$ versus $44 \%(P=.399)$ at 1 year. Similarly, the use of warfarin in the nonbox group versus the box group at 6 months was $48 \%$ versus $43 \%(P=.695)$ and at 1 year was $48 \%$ versus $50 \%(P=1.0)$.

The overall freedom from AF recurrence (Fig 3) was significantly higher in the box lesion group at 1 month's fol- low-up ( $87 \%$ vs $69 \%, P=.015)$ and at 3 months' follow-up (96\% vs $85 \%, P=.028)$. There was no statistical difference at 6 months and 1 year. However, in the box lesion group 100\% of patients were free from $\mathrm{AF}$ at 1 year. The freedom for $\mathrm{AF}$ recurrence in patients without antiarrhythmic drug use (Fig 4), on the other hand, was significantly higher in the box lesion group at 1 month's follow-up (47\% vs $22 \%, P=.004), 3$ months' follow-up (65\% vs $42 \%, P=.018)$, and 6 months' follow-up (79\% vs 54\%, $P=.011$ ). There was no statistically significant difference in the freedom from AF recurrence without antiarrhythmic drug use between the box lesion and the nonbox lesion groups at 1 year (83\% vs $61 \%, P=.138)$.

Finally, the use of antiarrhythmic drugs (Fig 5) was significantly less in the box lesion group at 3 months' follow-up (35\% vs 58\%, $P=.018)$ and 6 months' follow-up (15\% vs $44 \%, P=.002)$. Twice as many patients were taking
TABLE 3. Perioperative parameters

\begin{tabular}{lccc}
\hline \multicolumn{1}{c}{ Variables } & $\begin{array}{c}\text { Nonbox lesions } \\
\text { (n = 56) }\end{array}$ & $\begin{array}{c}\text { Box lesions } \\
(\mathbf{n}=\mathbf{8 1})\end{array}$ & $\boldsymbol{P}$ value \\
\hline Operative mortality (\%) & $2(3.6)$ & $2(2.5)$ & 1.0 \\
Mean CCT (min) & $78 \pm 35$ & $81 \pm 37$ & .602 \\
Mean CPB time (min) & $188 \pm 54$ & $180 \pm 48$ & .354 \\
Myocardial infarction (\%) & 0 & 0 & - \\
Stroke (\%) & 0 & $1(1.2)$ & .513 \\
Reoperation for bleeding (\%) & $7(12.5)$ & $3(3.7)$ & .091 \\
Permanent PM (\%) & $8(14.3)$ & $5(6.3)$ & .143 \\
Early ATA (\%) & $40(71.4)$ & $30(37.0)$ & $<.001$ \\
Median ICU LOS (d [range]) & $3(1-61)$ & $2(1-29)$ & .383 \\
Median hospital LOS & $11(4-61)$ & $9(4-54)$ & .074 \\
$\quad$ (d [range]) & & & \\
\hline
\end{tabular}

Operative mortality was defined as death within 30 days postoperatively. Permanent pacemaker placement was defined as patients receiving a pacemaker within 90 days postoperatively. Early atrial tachyarrhythmias included atrial fibrillation and atrial flutter. $C C T$, Crossclamp time; $C P B$, cardiopulmonary bypass; $P M$, pacemaker; $A T A$, atrial tachyarrhythmias; $I C U$, intensive care unit; $L O S$, length of stay.

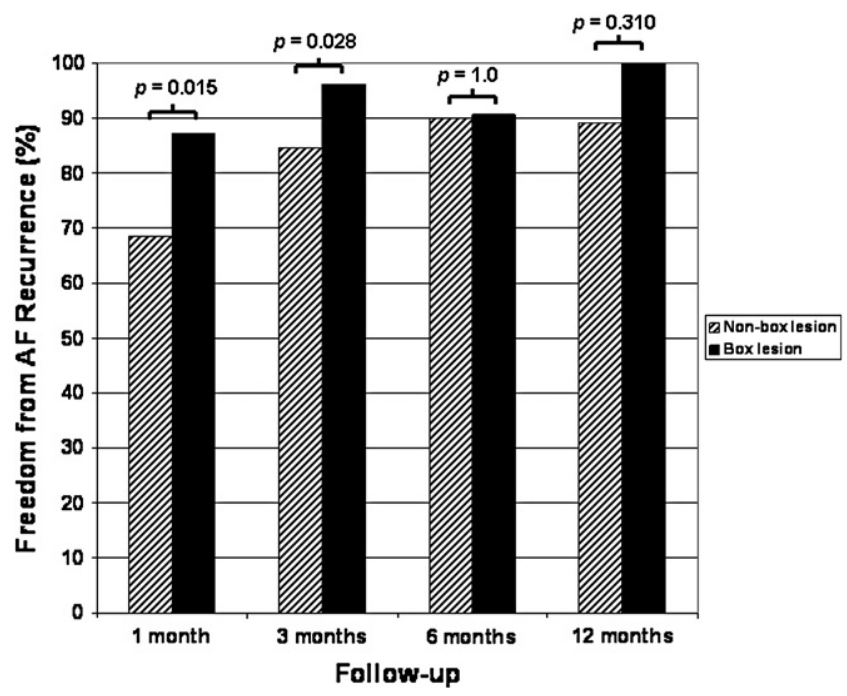

Figure 3. The overall freedom from atrial fibrillation (AF) recurrence was significantly higher for the box lesion group at 1 and 3 months. 


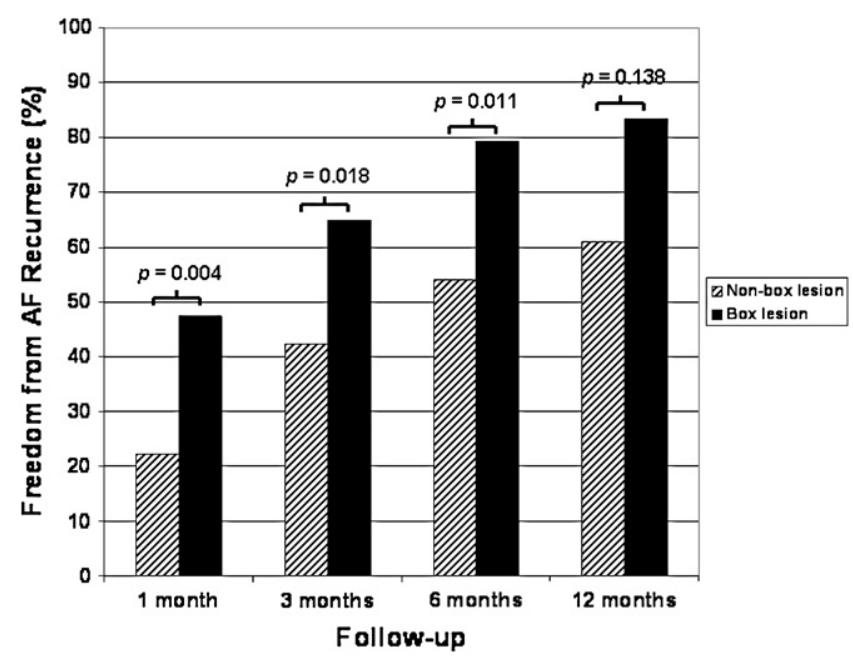

Figure 4. Freedom from atrial fibrillation (AF) recurrence in patients without antiarrhythmic drug use was significantly higher in the box lesion group at 1, 3, and 6 months.

antiarrhythmic drugs at 1 year in the nonbox lesion group versus the box lesion group (35\% vs $17 \%, P=.226$ ). However, this did not reach statistical significance.

\section{Discussion}

The lesion set in the ablation-assisted Cox maze IV procedure was designed to recapitulate the cut-and-sew Cox maze III incisions. ${ }^{17,20,23}$ The Cox maze procedure was originally designed as a single operation that would be effective in terminating AF in all patients. ${ }^{9}$ Because it was impossible to define the mechanism of $\mathrm{AF}$ in each patient before the operation, the lesion set in the Cox maze III procedure was empirically designed to interrupt all possible macroreentrant

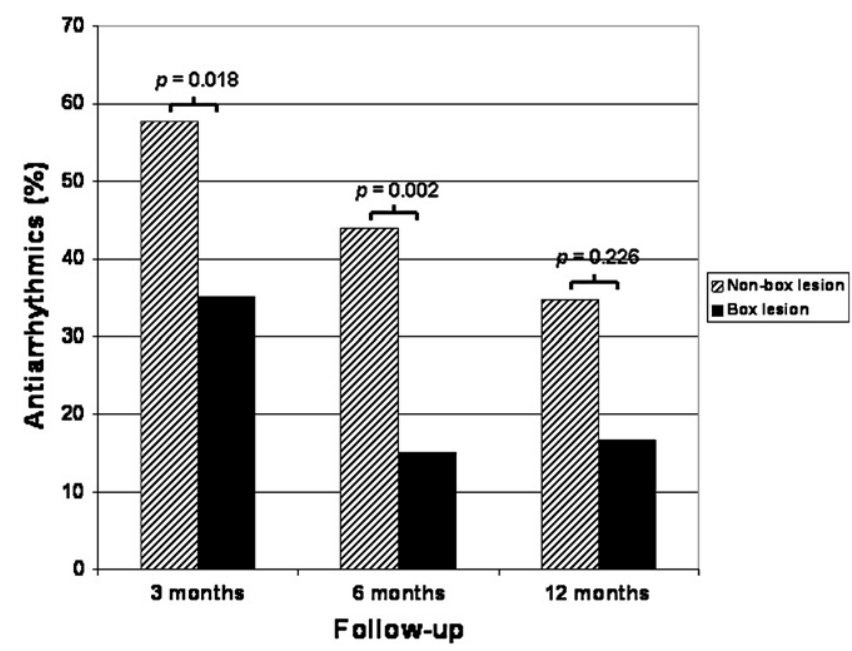

Figure 5. Use of antiarrhythmic drugs during follow-up was significantly lower in the box lesion group at 3 and 6 months. circuits. ${ }^{6,25,26}$ The particular importance of each incision has remained poorly defined.

The original cut-and-sew Cox maze III procedure isolated the pulmonary veins by creating one large incision that encircled all 4 pulmonary veins. This resulted in an akinetic, electrically isolated posterior left atrium. It was believed that this might have adverse functional consequences. Moreover, most of the focal triggers initiating AF originate in the pulmonary veins, ${ }^{27-29}$ and isolating the entire posterior left atrium was believed not to be necessary if the pulmonary veins and surrounding atria were effectively isolated. For these reasons, in the original Cox maze IV procedure, the superior and inferior pulmonary veins were isolated together as pairs on both the right and left sides by using bipolar radiofrequency ablation, and a single connecting ablation line was placed between the right and left inferior pulmonary veins (Figs 1 and 2). This method electrically isolated all 4 pulmonary veins individually but left the posterior left atrium in electrical continuity with the rest of the atrium, which was believed to be a more physiologic approach for preserving left atrial function.

Since June 2004, we routinely began to perform the Cox maze IV procedure by isolating the pulmonary veins as a box, effectively recreating the original circumferential incision line around all 4 pulmonary veins in the original Cox maze III procedure. This was done to see whether completely isolating the posterior left atrium would have an effect on our results. The box lesion was created by making an additional ablation line across the dome of the left atrium between the superior right and left pulmonary veins (Fig 2).

Data from this study demonstrated that the addition of a single extra ablation line to create the box lesion did not add any extra crossclamp or cardiopulmonary bypass time. This is not surprising in that the time for a single bipolar radiofrequency ablation averaged $11.1 \pm 4.3$ seconds. ${ }^{30}$ There was also no effect on postoperative morbidity and mortality.

The most dramatic finding of this study was that isolating the entire posterior left atrium instead of only the individual pulmonary veins during the Cox maze IV procedure resulted in a significant decrease in the incidence of early postoperative atrial tachyarrhythmia. The incidence was decreased by $48 \%$. This likely was the reason for the shorter median length of hospital stay in the box lesion group because the management was simplified without the occurrence of postoperative atrial tachyarrhythmias.

Late recurrence of AF was lower at 3 months in the box lesion group. Although there was no difference in recurrence of AF between the 2 groups at 6 and 12 months, there was less use of antiarrhythmic drugs at both time points. This is likely an indicator of less recurrent atrial arrhythmias but did not correlate with significantly less recurrent $\mathrm{AF}$ at these time points. This probably is a reflection of the posterior left atrium being an important source for the triggers responsible for the initiation and the drivers required for the maintenance 
of $\mathrm{AF}^{31,32}$ Indeed, recent evidence has accumulated in the catheter ablation literature regarding the importance of the posterior left atrium because isolating the posterior left atrium instead of only the pulmonary veins has been associated with better results. ${ }^{33}$ Another explanation for the decreased incidence of atrial arrhythmias in the box lesion group is the reduction of the critical mass available for the circulating wavelets responsible for sustaining AF. Our laboratory has shown that there is a defined atrial area required to sustain $\mathrm{AF}$ in isolated canine atria. ${ }^{34}$ If the atrial area was less than this critical amount, $\mathrm{AF}$ was unable to be induced. ${ }^{34}$

\section{Study Limitations}

There were several limitations to this study. The data were prospectively collected, but patients were not randomized to each group. Therefore there might have been a selection bias. However, both groups consisted of unselected consecutive referrals for a Cox maze IV procedure at our institution. Furthermore, there were no statistically significant differences in the preoperative demographics between the 2 groups. Although the small difference $(0.5 \mathrm{~cm})$ in the mean left atrial diameter between the 2 groups almost reached statistical significance $(P=.055)$, it is unlikely that this had an effect on the success of the operation. ${ }^{34}$

There also was a significant difference in the mean followup between the 2 groups that were compared. This reflects the fact that the nonbox lesion group was almost exclusively from before June 2004, and the box lesion has been performed since June 2004 until the present time. Patients were compared at fixed time points postoperatively rather than at last follow-up to overcome this bias. Nevertheless, the possibility of better surgical results from a more recent study group because of more experience cannot be absolutely excluded. However, there was no difference in the operative mortality, in the mean cardiopulmonary bypass time, or in the mean crossclamp time between the 2 groups. Also, all of the cases were performed by a single surgeon (R.J.D.), who has been performing the Cox maze procedure for more than 15 years. It is unlikely that any learning curve phenomenon was involved in the differences between groups. Finally, the number of patients in each group was relatively small. However, follow-up was $100 \%$ complete, and the entire study population was more than 130 patients.

\section{Conclusions}

This study demonstrated that completely isolating the posterior left atrium as a box around the pulmonary veins instead of a single connecting lesion was associated with significantly fewer postoperative atrial tachyarrhythmias and a higher freedom from AF recurrence at 1 and 3 months. The box lesion group also had the advantage of less antiarrhythmic drug use at 3 and 6 months postoperatively. Creating the box lesion during the Cox maze IV procedure did not increase operative time or postoperative morbidity and mor- tality. Therefore the box lesion should be performed to isolate the posterior left atrium in all patients undergoing the Cox maze IV procedure.

\section{References}

1. Thom T, Haase N, Rosamond W, Howard VJ, Rumsfeld J, Manolio T, et al. Heart disease and stroke statistics_-2006 update: a report from the American Heart Association Statistics Committee and Stroke Statistics Subcommittee. Circulation. 2006;113:e85-151.

2. Feinberg WM, Blackshear JL, Laupacis A, Kronmal R, Hart RG. Prevalence, age distribution, and gender of patients with atrial fibrillation. Analysis and implications. Arch Intern Med. 1995;155:469-73.

3. Wattigney WA, Mensah GA, Croft JB. Increasing trends in hospitalization for atrial fibrillation in the United States, 1985 through 1999: implications for primary prevention. Circulation. 2003;108:711-6.

4. Wolf PA, Abbott RD, Kannel WB. Atrial fibrillation as an independent risk factor for stroke: the Framingham Study. Stroke. 1991;22:983-8.

5. Risk factors for stroke and efficacy of antithrombotic therapy in atrial fibrillation. Analysis of pooled data from five randomized controlled trials. Arch Intern Med. 1994;154:1449-57.

6. Cox JL, Schuessler RB, D'Agostino HJ Jr, Stone CM, Chang BC, Cain ME, et al. The surgical treatment of atrial fibrillation. III. Development of a definitive surgical procedure. J Thorac Cardiovasc Surg. 1991;101:569-83

7. Cox JL, Boineau JP, Schuessler RB, Jaquiss RD, Lappas DG. Modification of the maze procedure for atrial flutter and atrial fibrillation. I. Rationale and surgical results. J Thorac Cardiovasc Surg. 1995;110: 473-84.

8. Cox JL, Schuessler RB, Lappas DG, Boineau JP. An 8 1/2-year clinical experience with surgery for atrial fibrillation. Ann Surg. 1996;224: 267-73.

9. Prasad SM, Maniar HS, Camillo CJ, Schuessler RB, Boineau JP, Sundt TM 3rd, et al. The Cox maze III procedure for atrial fibrillation: long-term efficacy in patients undergoing lone versus concomitant procedures. J Thorac Cardiovasc Surg. 2003;126:1822-8.

10. Viola N, Williams MR, Oz MC, Ad N. The technology in use for the surgical ablation of atrial fibrillation. Semin Thorac Cardiovasc Surg. 2002; 14:198-205.

11. Khargi K, Hutten BA, Lemke B, Deneke T. Surgical treatment of atrial fibrillation; a systematic review. Eur J Cardiothorac Surg. 2005;27: 258-65.

12. Williams MR, Garrido M, Oz MC, Argenziano M. Alternative energy sources for surgical atrial ablation. J Card Surg. 2004;19:201-6.

13. Cummings JE, Pacifico A, Drago JL, Kilicaslan F, Natale A. Alternative energy sources for the ablation of arrhythmias. Pacing Clin Electrophysiol. 2005;28:434-43.

14. Prasad SM, Maniar HS, Schuessler RB, Damiano RJ Jr. Chronic transmural atrial ablation by using bipolar radiofrequency energy on the beating heart. J Thorac Cardiovasc Surg. 2002;124:708-13.

15. Prasad SM, Maniar HS, Diodato MD, Schuessler RB, Damiano RJ Jr. Physiological consequences of bipolar radiofrequency energy on the atria and pulmonary veins: a chronic animal study. Ann Thorac Surg. 2003;76:836-41.

16. Gaynor SL, Ishii Y, Diodato MD, Prasad SM, Barnett KM, Damiano NR, et al. Successful performance of Cox-Maze procedure on beating heart using bipolar radiofrequency ablation: a feasibility study in animals. Ann Thorac Surg. 2004;78:1671-7.

17. Gaynor SL, Diodato MD, Prasad SM, Ishii Y, Schuessler RB, Bailey MS, et al. A prospective, single-center clinical trial of a modified Cox maze procedure with bipolar radiofrequency ablation. $J$ Thorac Cardiovasc Surg. 2004;128:535-42.

18. Mokadam NA, McCarthy PM, Gillinov AM, Ryan WH, Moon MR, Mack MJ, et al. A prospective multicenter trial of bipolar radiofrequency ablation for atrial fibrillation: early results. Ann Thorac Surg. 2004;78: 1665-70.

19. Gaynor SL, Schuessler RB, Bailey MS, Ishii Y, Boineau JP, Gleva MJ, et al. Surgical treatment of atrial fibrillation: predictors of late recurrence. J Thorac Cardiovasc Surg. 2005;129:104-11. 
20. Melby SJ, Kaiser SP, Bailey MS, Zierer A, Voeller RK, Lall SC, et al. Surgical treatment of atrial fibrillation with bipolar radiofrequency ablation: mid-term results in one hundred consecutive patients. J Cardiovasc Surg (Torino). 2006;47:705-10.

21. Melby SJ, Zierer A, Bailey MS, Cox JL, Lawton JS, Munfakh N, et al. A new era in the surgical treatment of atrial fibrillation: the impact of ablation technology and lesion set on procedural efficacy. Ann Surg. 2006;244:583-92.

22. Lall SC, Melby SJ, Voeller RK, Zierer A, Bailey MS, Guthrie TJ, et al. The effect of ablation technology on surgical outcomes after the Coxmaze procedure: a propensity analysis. $J$ Thorac Cardiovasc Surg. 2007:133:389-96.

23. Damiano RJ Jr, Gaynor SL. Atrial fibrillation ablation during mitral valve surgery using the Atricure device. Oper Tech Thorac Cardiovasc Surg. 2004;9:24-33.

24. Voeller RK, Schuessler RB, Damiano RJ Jr. Surgical treatment of atrial fibrillation. In: Cohn LH, editor. Cardiac surgery in the adult. 3rd ed. New York: McGraw-Hill; 2008. p. 1375-93.

25. Cox JL, Schuessler RB, Boineau JP. The surgical treatment of atrial fibrillation. I. Summary of the current concepts of the mechanisms of atrial flutter and atrial fibrillation. J Thorac Cardiovasc Surg. 1991;101:402-5.

26. Cox JL, Canavan TE, Schuessler RB, Cain ME, Lindsay BD, Stone C, et al. The surgical treatment of atrial fibrillation. II. Intraoperative electrophysiologic mapping and description of the electrophysiologic basis of atrial flutter and atrial fibrillation. J Thorac Cardiovasc Surg. 1991; 101:406-26.

27. Haissaguerre M, Jais P, Shah DC, Takahashi A, Hocini M, Quiniou G, et al. Spontaneous initiation of atrial fibrillation by ectopic beats originating in the pulmonary veins. N Engl J Med. 1998;339:659-66.

28. Schmitt C, Ndrepepa G, Weber S, Schmieder S, Weyerbrock S, Schneider M, et al. Biatrial multisite mapping of atrial premature complexes triggering onset of atrial fibrillation. Am J Cardiol. 2002;89: 1381-7.

29. Chen SA, Hsieh MH, Tai CT, Tsai CF, Prakash VS, Yu WC, et al. Initiation of atrial fibrillation by ectopic beats originating from the pulmonary veins: electrophysiological characteristics, pharmacological responses, and effects of radiofrequency ablation. Circulation. 1999; 100:1879-86.

30. Melby SJ, Zierer A, Voeller RK, Lall SC, Bailey MS, Moon MR, et al. Wide variations in energy delivery using an impedence-controlled algorithm in bipolar radiofrequency ablation: evidence against fixed time ablation. Innovations. 2007;2:67-72.

31. Ndrepepa G, Schneider MA, Karch MR, Weber S, Schreieck J, Schomig A, et al. Pulmonary vein internal electrical activity does not contribute to the maintenance of atrial fibrillation. Pacing Clin Electrophysiol. 2003;26:1356-62.

32. Mansour M, Mandapati R, Berenfeld O, Chen J, Samie FH, Jalife J. Leftto-right gradient of atrial frequencies during acute atrial fibrillation in the isolated sheep heart. Circulation. 2001;103:2631-6.

33. Oral H, Scharf C, Chugh A, Hall B, Cheung P, Good E, et al. Catheter ablation for paroxysmal atrial fibrillation: segmental pulmonary vein ostial ablation versus left atrial ablation. Circulation. 2003;108:2355-60.

34. Byrd GD, Prasad SM, Ripplinger CM, Cassilly TR, Schuessler RB, Boineau JP, et al. Importance of geometry and refractory period in sustaining atrial fibrillation: testing the critical mass hypothesis. Circulation. 2005;112(suppl):I7-13.

\section{Discussion}

Dr Ottavio Alfieri (Milan, Italy). This study, very well presented by Dr Voeller, is another important contribution coming from a leading institution with a great tradition and an ongoing prominent scientific production in the field of surgical treatment of AF. The Cox maze III operation has been repeatedly and consistently shown to be the most effective curative therapy for AF. Although the reproduction of the standard cut-and-sew procedure using bipolar radiofrequency to create atrial lesions has been associated with similar results in a pro- pensity analysis conducted by the authors, this has not been the case in other experiences.

At the Mayo Clinic, for instance, the superiority of the cut-andsew method over the radiofrequency variant has been clearly documented in a case-matched study. Therefore efforts to increase the effectiveness of the bipolar radiofrequency ablation procedure, the so-called Cox maze IV operation, are fully justified.

There are several reasons to believe that the addition of a second connecting line is a good move. First, the box lesion is mimicking more closely the original cut-and-sew Cox maze III operation, in which a large incision is encircling all 4 pulmonary veins.

Second, the box lesion is achieving a more considerable reduction of the critical mass necessary to sustain AF.

Third, the posterior free wall of the left atrium is recognized as a common site of nonpulmonary vein triggers of AF.

Fourth, it is always possible that the single connecting ablation line is not producing a complete transmural lesion. Although we are generally confident to produce transmural lesions with bipolar radiofrequency, we never know for sure, particularly when the atrial wall is thick, fibrotic, and with a lot of fatty tissue. Furthermore, the transmurality of that connecting line, which is created on an arrested heart, is never evaluated electrophysiologically.

Fifth, it is likely that a complete isolation of the posterior left atrium is producing more functional exclusion of epicardial ganglionated plexuses, which has been recognized to have a role in the initiation and maintenance of AF.

I have a couple of questions for Dr Voeller. First, the negative aspect of the box lesion is the possible adverse effect on left atrial function because a large area of akinetic electrically isolated left atrium is created. Did you investigate the left atrial function with specific methods in the 2 groups of patients?

My other question is related to the use of antiarrhythmic drugs. A significant reduction in the use of antiarrhythmic drugs was obtained in the box lesion groups at 3 and 6 months' follow-up. This is an important achievement, which is convincing only if precise and rigorous protocols of antiarrhythmic drug administrations are consistently applied over time. Can you tell us which have been the criteria to give and to stop the antiarrhythmic drugs in your study?

Thank you, and again, congratulations for this excellent article.

Dr Voeller. Thank you, Dr Alfieri, for your kind words. We feel very honored to have you discuss our studies, and those are excellent questions. To try to answer your first question, obviously our overall goal is to do an operation that has a high success rate yet preserves the normal left atrial function physiologically and mechanically as much as possible, and there is no question that doing a Cox maze procedure does have some sort of effect on left atrial function. Unfortunately, there are not a lot of studies out there that have systematically and in detail looked at this question. We are actually in the process of looking at this clinically and experimentally using noninvasive magnetic resonance imaging.

Could have my slide up once again please? We do have some preliminary data from 3 maze patients who underwent preoperative and 30-day postoperative cardiac magnetic resonance imaging to look at atrial function and how that is affected from the Cox maze procedure, and our preliminary results show that reservoir function, as well as booster pump function, are both negatively affected to a certain extent at least 30 days after the operation. The conduit 
function actually picks up the diminished reservoir and booster pump function. Therefore the maze procedure does have a negative effect on atrial function, and further studies are necessary and more data are required to really know what happens to atrial function and how long the negative effects persist after the maze procedure.

Having said that, these negative effects on atrial function probably do not have a large clinical meaning in patients, at least those with a structurally normal heart with normal left ventricular function, but that is sort of early to say.

With regard to the posterior left atrium specifically, the reason why we initially did not do a box lesion early in this series was because of the fear that producing an akinetic posterior wall by isolating the posterior left atrium, which accounts for about a third of the total left atrial mass, created a negative effect on the overall left atrial function, and some authors have actually further stated that this could actually create an environment for thrombus formation and put the patient at risk of stroke. However, having said that, in our experience of doing the Cox maze procedure at Barnes-Jewish Hospital for 20 years now, our incidence of postoperative stroke has been extremely low, less than $0.1 \%$ per year, and at long-term follow-up, well over $90 \%$ of our patients are off warfarin. Therefore we are pretty confident that this posterior left atrial wall akinesis caused by the box lesion has very little clinical significance, at least in our experience.

To try to answer your second question, we do have strict guidelines in terms of antiarrhythmic use after the operation. In patients who are in normal sinus rhythm after the operation, those patients are all started on antiarrhythmic drugs, preferably amiodarone, for 2 months. Patients obviously in AF after the operation are also started on antiarrhythmic drugs. For patients who are in bradycardia or junctional rhythm, we do not start them on antiarrhythmic drugs routinely.

At 2 months we obtain an electrocardiogram, and if the patients are in normal sinus rhythm at that point, we stop the antiarrhythmic drugs at 2 months. Four weeks after that, so at 3 months' follow-up, we get a 24-hour prolonged Holter monitoring at this time, and if they still remain in sinus rhythm, we stop the warfarin at that point, at 3 months.

Dr Niv Ad (Falls Church, Va). This is an excellent study and a very important one. I wonder whether you looked at the subgroup of patients in whom the nonboxed lesion failed in more detail. In other words, were they different and more prone to failure with regard to the existence of the number of traditional risk factors for failure? That is to say, this study might miss the real reason for failure because of the fact that those variables were not assessed: larger atria, longer duration of AF, or both. Our practice is to apply the nonboxed lesion in so-called regular-sized or a little bit oversized left atria; however, we use a full box lesion and more in those patients with larger atria. Did you find any correlation?

Dr Voeller. In terms of left atrial size and failure?

Dr Ad. In this specific subgroup of patients in whom failure occurred, did they have larger atria and longer durations of AF that might suggest that it is not the lesion that was the strongest predictor for failure but the subset of patients? I think that this is a very important group and more interesting than many other groups that we are reporting about.
Dr Voeller. We did not look at that specifically. As you mentioned, the left atrial size was slightly smaller in the box lesion group. The mean size was $5.3 \mathrm{~cm}$, as opposed to $5.8 \mathrm{~cm}$ in the nonbox lesion group. But we did not investigate your specific question in this study.

Dr Takashi Nitta (Tokyo, Japan). Your data have proved the hypothesis of mass theory in AF. The more atrium you isolate, the higher success rate for AF you get. But we also have to think about left atrial function, as Dr Alfieri has noted, because the purpose of AF surgery is not only in the restoration of sinus rhythm but also in the restoration of significant left atrial transport function to prevent thromboembolic events.

We have shown in an animal study that isolation of the posterior left atrium results in about a $20 \%$ to $30 \%$ reduction of the left atrial transport function compared with bilateral pulmonary vein isolation. For this reason, I think it is too early to conclude that the box lesion should be performed in all patients undergoing the Cox maze procedure. I think you can map the posterior left atrium with a mapping system to define the patients in whom we really need to isolate the posterior left atrium. Have you ever mapped the patients to examine whether abnormal activation or reentry arises from the posterior left atrium?

Dr Voeller. We clinically have not done that.

Dr Damiano. Dr Nitta, what you are asking is whether we have ever performed intraoperative mapping?

Dr Nitta. Right. Your data have suggested that some patients might have some kind of triggers or reentry in the posterior left atrium. Have you ever proved that electrophysiologically?

Dr Damiano. We have performed intraoperative mapping on between 50 and 60 patients over the years, and we have definitely seen rotors that have involved areas of the posterior left atrium, but as opposed to your group, we have not used it to guide therapy in any way. Most of our maps are generated retrospectively. But clearly, we have shown, as have many others, as Dr Alfieri pointed out, that the posterior left atrium is an important site of triggers, nonpulmonary vein triggers, for paroxysmal AF. We have also seen, both in our intraoperative mapping and now in body-surface mapping, that this area is very involved in the creation and maintenance of the rotors, which are involved in sustained atrial function.

Dr Masashi Komeda (Kyoto, Japan). Anatomy teaches us that the posterior left atrial wall, the area surrounded by those 4 pulmonary vein orifices, is embryologically a part of the pulmonary vein, and thus there is not much muscle. Therefore basically creating a box lesion does not compromise left atrial function so much. In our atrial volume reduction maze surgery, we just ignore the function of that posterior left atrial part, but we still have good results. Just a comment.

Dr Voeller. Thank you very much for that comment. I actually had a slide that I wanted to show you from a magnetic resonance imaging study looking at the 4-chamber view of the heart, and it clearly shows that the posterior portion of the left atrium does not move under normal circumstances, or the movement is very little, because the posterior wall is tethered to the posterior mediastinum by the pulmonary veins. But creating a box lesion and creating that area being akinetic, it probably has very little mechanical consequence. 